\title{
Long Lead Time Drought Forecasting Using a Wavelet and Fuzzy Logic Combination Model: A Case Study in Texas
}

\author{
MEHMET ÖZGER \\ Department of Biological and Agricultural Engineering, Texas A\&M University, College Station, Texas, and Hydraulics Division, \\ Civil Engineering Department, Istanbul Technical University, Istanbul, Turkey \\ ASHOK K. MisHRA \\ Department of Biological and Agricultural Engineering, Texas A\&M University, College Station, Texas \\ VIJAY P. SINGH \\ Department of Biological and Agricultural Engineering, and Department of Civil and Environmental Engineering, \\ Texas A\&M University, College Station, Texas
}

(Manuscript received 6 October 2010, in final form 7 July 2011)

\begin{abstract}
Drought forecasting is important for drought risk management. Considering the El Niño-Southern Oscillation (ENSO) variability and persistence in drought characteristics, this study developed a wavelet and fuzzy logic (WFL) combination model for long lead time drought forecasting. The idea of WFL is to separate each predictor and predictand into their frequency bands and then reconstruct the predictand series by using its predicted bands. The strongest-frequency bands of predictors and predictand were determined from the average wavelet spectra. Applying this combination model to the state of Texas, it was found that WFL had a significant improvement over the fuzzy logic model that did not use wavelet banding. Comparison with an artificial neural network (ANN) model and a coupled wavelet and ANN (WANN) model showed that WFL was more accurate for drought forecasting. Also, it should be noted that the ENSO variability is not a global precursor of drought. For this reason, prior to an application of such a data-driven model in different regions, significant work is required to identify appropriate independent predictors. Drought forecasting with longer lead times and higher accuracy is of significant value in engineering applications.
\end{abstract}

\section{Introduction}

Drought forecasting is a critical element in drought risk management. The importance of drought forecasting is being heightened by the scarcity of water occurring too frequently around the world in recent years (Mo et al. 2009). The success of drought preparedness and mitigation depends, to a large extent, upon timely information on the drought onset and development in time and space. This information may be obtained through continuous drought monitoring, which is normally performed using drought indices.

Corresponding author address: Mehmet Özger, Dept. of Civil Engineering, Istanbul Technical University, Istanbul, 34469, Turkey.

E-mail: mehmetozger@yahoo.com
Many drought forecasting models have been developed in recent years (Mishra and Singh 2010, 2011). Rao and Padmanabhan (1984) investigated the stochastic nature of yearly and monthly Palmer drought indexes (PDIs) and characterized that using stochastic models to forecast and simulate the PDI series. Lohani and Loganathan (1997) used the Palmer drought severity index (PDSI) to characterize the stochastic behavior of droughts. Cancelliere et al. (2005) forecasted standard precipitation index (SPI) values using an autocovariance matrix of the SPI time series. Mishra and Desai (2005) developed autoregressive integrated moving average (ARIMA) and multiplicative seasonal ARIMA models to forecast droughts using an SPI series. These models satisfactorily forecast droughts up to 2 months of lead time.

Artificial neural network (ANN) models, which are useful for modeling time series, have recently been used 
for drought forecasting. Morid et al. (2007) developed an approach for drought forecasting using an ANN. The indices used were the effective drought index (EDI) and SPI. Forecasts were made using different combinations of past rainfall, EDI, and SPI in the preceding months and climate indices, such as the Southern Oscillation index (SOI) and North Atlantic Oscillation (NAO) index. ANN models for both EDI and SPI had $R^{2}$ values of 0.66-0.79 for a lead time of 6 months. Morid et al. (2007) also showed that forecasts using EDI were superior to those using SPI for all lead times and at all rainfall stations. The better performance using EDI was illustrated by its more accurate prediction of the overall pattern of "dry" and "wet" conditions. Mishra and Desai (2006) compared linear stochastic models with a recursive multistep neural network and a direct multistep neural network for up to 6-month lead time and found that the recursive multistep model was best suited for 1-monthahead prediction. When a longer lead time of 4 months was considered, the direct multistep model outperformed the recursive multistep and ARIMA models. Barros and Bowden (2008) employed self-organizing maps (SOM) and multivariate linear regression analysis to forecast standard precipitation index within the Murray-Darling basin (MDB) in Australia up to 12 months in advance.

Hybrid models are useful for drought forecasting with long lead times. Mishra et al. (2007) developed a hybrid model, combining an ARIMA model and a nonlinear artificial neural network (feed-forward recursive multistep) for drought forecasting. The hybrid model combined the advantages of both stochastic and ANN models. Using the SPI series, hybrid models as well as individual stochastic and ANN models were applied to forecast droughts in the Kansabati River basin in India, and their performances were compared. The hybrid model was found to forecast droughts with greater accuracy up to a 6-month lead time.

Fuzzy logic is also preferred sometimes when linking inputs to outputs in a nonlinear manner. Since its first proposal by Zadeh (1965), it has been applied in a variety of areas. Pesti et al. (1996) modeled the relationship between drought characteristics and general circulation patterns (CP) using fuzzy logic. Pongracz et al. (1999) applied fuzzy rule-based modeling for the prediction of regional droughts using two forcing inputs: ENSO (El NiñoSouthern Oscillation) and large-scale atmospheric CPs in a typical Great Plains state-Nebraska. These fuzzy models are applicable for only short-term drought forecasting.

One of the recently used approaches in statistical forecasting is to decompose the predictor and predictand time series into its major subseries and then build the forecasting model (Rajagopalan et al. 1998; Kim and Valdes 2003; Webster and Hoyos 2004; Kwon et al. 2007).
Wavelet transforms have been employed frequently as a common tool for analyzing local variations in time series (Kumar and Foufoula-Georgiou 1997; Torrence and Compo 1998; Saco and Kumar 2000; Jevrejeva et al. 2003; Gan et al. 2007; Küçük et al. 2009). Zhang and Dong (2001), Aussem and Murtagh (1997), Kim and Valdes (2003), and Partal and Cigizoglu (2008, 2009) combined wavelet transforms with neural networks, Zheng et al. (2000) with Kalman filters, Zhou et al. (2008) with ARIMA models, and Partal and Kisi (2007) with fuzzy logic. Wavelet transforms have an ability to decompose the original time series into various resolution levels that capture valuable information. Generally, the performance of a forecasting model improves when the information at different temporal scales is used.

It is well known that there is a teleconnection between hydrometeorological events in the continental United States and ENSO indices, such as SOI and sea surface temperatures (SSTs) (Kahya and Dracup 1993, 1994; Cole et al. 2002; Barlow et al. 2001; Tadesse et al. 2005; Tootle et al. 2005; Alfaro et al. 2006; Tootle and Piechota 2006; Busby et al. 2007; Feng et al. 2008; Coelho and Goddard 2009). Texas is affected from oscillations occurring in the tropical Pacific region (Özger et al. 2009). ENSO affects Pacific moisture patterns and leads to long-term (decadal) changes in precipitation in Texas. It can induce periods of moderate to severe droughts. Generally a weak oscillation causes below-average precipitation and some degree of drought. In contrast, Texas usually experiences above-average precipitation when a strong oscillation is recorded. Rajagopalan et al. (2000) reported that during the first three decades of the twentieth century, summer drought teleconnections in response to SST patterns linked to ENSO were found to be the strongest in the southern region of Texas.

The probabilistic quarterly seasonal forecasts of global climate by the International Research Institute for Climate Prediction (IRI) (more information available online at http://iri.columbia.edu/climate/forecast/net_asmt/) began issuing useful information for many parts of the world and these are quite useful for agriculture, energy, and water resources sectors (Goddard et al. 2003). Most models forecast droughts with high accuracy for short lead times (less than 3 months), and those forecasting droughts for 6-12 months do not yield satisfactory forecasts. This study focuses on long-term drought forecasting. Extending the forecasting of monthly drought indices up to 12-month lead time is the main objective of this study. This is accomplished by employing a waveletfuzzy logic combination model. Long-range seasonal drought forecasting considers lagged values of drought indices along with the Niño-3.4 $\left(5^{\circ} \mathrm{N}-5^{\circ} \mathrm{S}, 170^{\circ}-120^{\circ} \mathrm{W}\right)$ index representing the SST anomalies. 


\section{Data}

The intensity and spatial extent of droughts are generally quantified by drought indices. PDSI, as a measure of meteorological drought, is one of the most commonly used climatic drought indices in the United States (Palmer 1965; Alley 1984). PDSI is based on the principle of balance between moisture supply and demand, when man-made changes are not considered. This index takes into account the length and severity of a wet or dry spell (Heddinghaus and Sabol 1991). The greater the absolute value the more severe the dry or the wet spell. PDSI was modified by the National Weather Service Climate Analysis Center to obtain another index-modified PDSI, or the Palmer modified drought index (PMDI). PMDI is the operational version of PDSI that allows computation of PDSI operationally by taking the sum of the wet and dry terms after they have been weighted by their probabilities (Heim 2002); the description is available in Heddinghaus and Sabol (1991) and some of the studies based on PMDI include Rhee and Carbone (2007) and Hiller and Powell (2009).

Long datasets and unimpaired series are preferred for application of the wavelet fuzzy logic (WFL) model. PMDI was used as a drought indicator in this study. The PMDI time series used in this study are the average values across Texas. Statewide monthly mean temperature and total precipitation for Texas are used to calculate PMDI values. Monthly PMDI values, which are available from 1895 to 2007, were retrieved from the National Climatic Data Center of the National Oceanic and Atmospheric Administration (NOAA).

The monthly time series of the Niño-3.4 (1951-2007) index were used in this study (NOAA 2008). The Niño3.4 index, which is the mean sea surface temperature throughout the equatorial Pacific east of the date line $\left(5^{\circ} \mathrm{N}-5^{\circ} \mathrm{S}, 170^{\circ}-120^{\circ} \mathrm{W}\right)$, was used to characterize the nature of ENSO. In this study, the Niño-3.4 index and persistence in PMDI were used as predictor variables. Future PMDI values (predictand) were forecasted using these variables.

\section{WFL combination model}

\section{a. The continuous wavelet transform}

The wavelet transform provides multiresolution of a signal in time and frequency domains and has been employed for studying nonstationary time series, where it is difficult to detect the time of occurrence of a particular event if a Fourier transform (FT) is used. Gabor
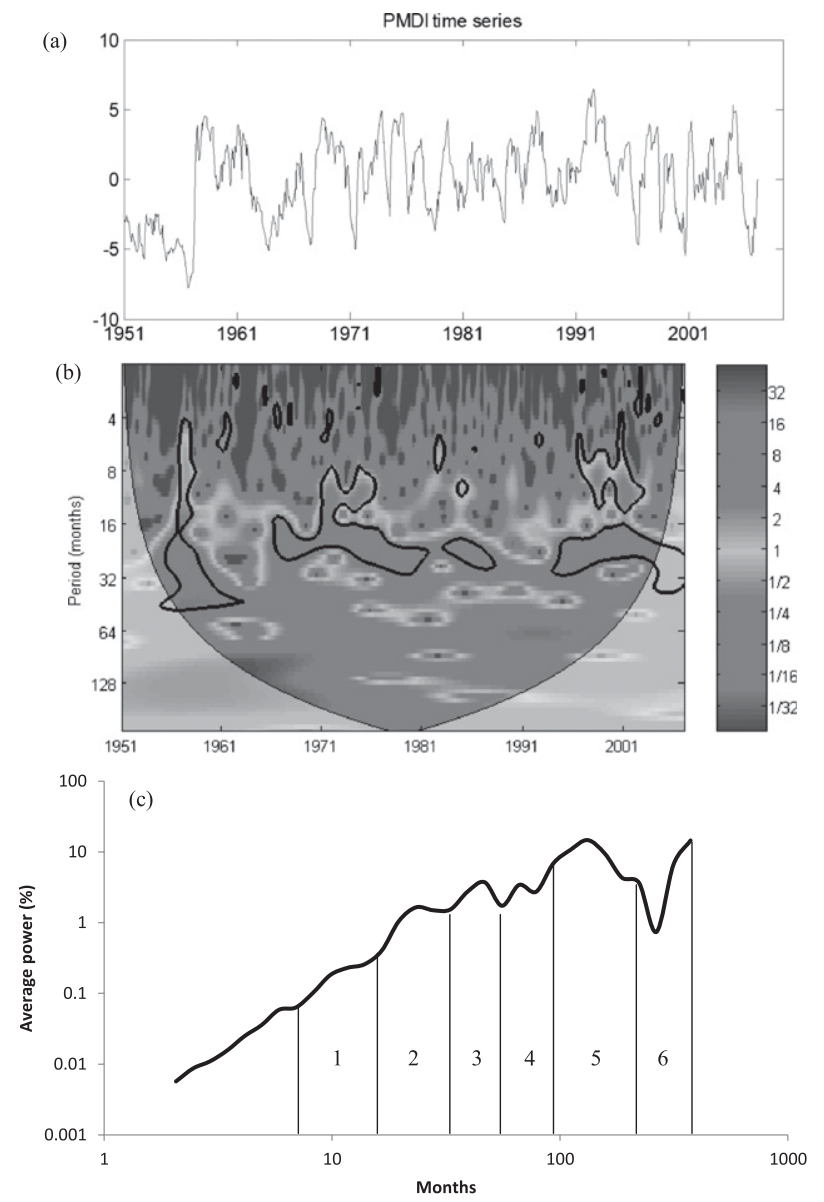

FIG. 1. (a) PMDI time series, (b) continuous wavelet transform of PMDI, and (c) average wavelet spectra.

(1946) introduced a local Fourier transform to analyze a small section of a signal at a time with sliding windows, which provide some information about the time and frequency of the signal. However, this method assumes that coherent time should be independent of the frequency and only a limited precision can be determined with respect to the size of window (Misiti et al. 2000). Wavelet analysis has the capability to employ long time intervals for low-frequency information and shorter intervals for high-frequency information. Since the ENSO indicators (Niño-3.4 index) and drought occurrence have long time intervals to develop, low-frequency components gain importance in comparison with high frequency.

For the wavelet transform, first a wavelet function $\psi(t)$ called mother wavelet is defined. The function is used for both wavelet decomposition and composition transforms (Torrence and Compo 1998). In this study, the Morlet wavelet was used and the future information was padded with zeros. 

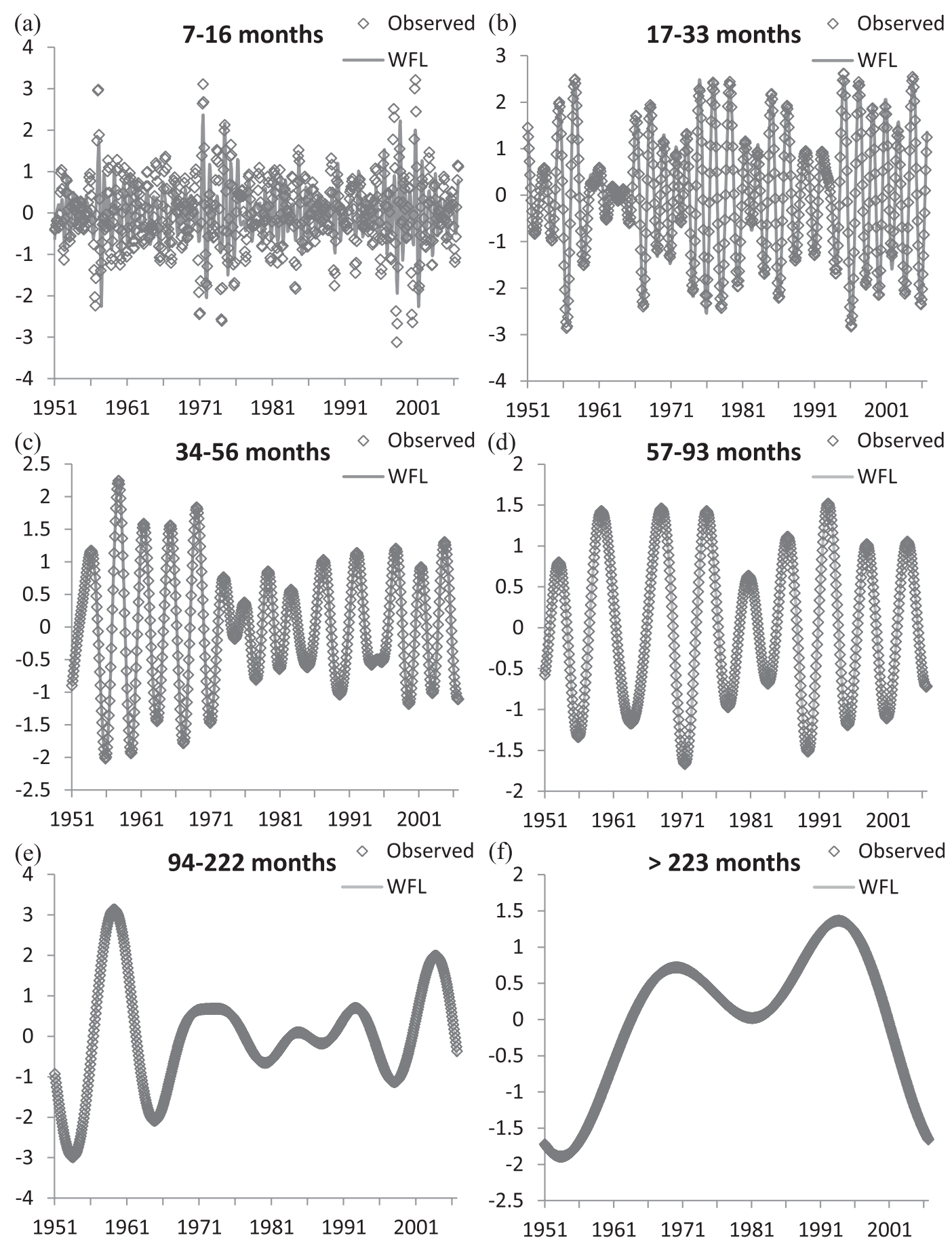

FIG. 2. Significant spectral bands of observed PMDI values and their prediction by WFL. These bands are (a) 7-16, (b) 17-33, (c) 34-56, (d) 57-93, (e) 94-222, and (f) $>223$ months.

High-frequency components of the Niño-3.4 index and PMDI series are detected with lower scales that refer to a compressed wavelet. Also, the behavior of the low-frequency component of signals can be determined by evaluating higher scales composed of the stretched version of a wavelet.

\section{b. Determination of significant bands from the wavelet transform}

A measured time series consists of several frequencies. The prediction sometimes can be difficult if the whole time series is taken into account without separation into 
frequency bands and elimination of noise. The approach may be that one can use only significant frequencies in the prediction scheme to obtain more accurate results. Webster and Hoyos (2004) suggested the use of significant variances in the wavelet spectra for the separation of frequency bands. The PMDI time series (Fig. 1a), which is considered as predictand, and its corresponding continuous wavelet transform along with the wavelet spectra are shown in Figs. 1b and 1c, respectively. It is evident from the figure that there are six distinct frequency bands, which are 7-16, 17-33, 34-56, 57-93, 94222 , and $>223$ months. The time series of wavelet bands are obtained by inverse wavelet filtering (Fig. 2). The Morlet wavelet is employed for wavelet analysis. The frequency bands obtained from the wavelet transform of predictand are used for other predictors. There are six bands that should be predicted from their corresponding predictors. As a final step, these predicted bands are reconstructed to establish the desired PMDI time series.

\section{c. Fuzzy logic}

The fuzzy logic (FL) theory has been applied in engineering, economics, social, and medical sciences. In contrast with the classical set theory where one element either belongs to a set or not, in the fuzzy set theory one element can be a member of one or more sets at the same time with varying membership degrees. FL is capable of linking multiple inputs to one output.

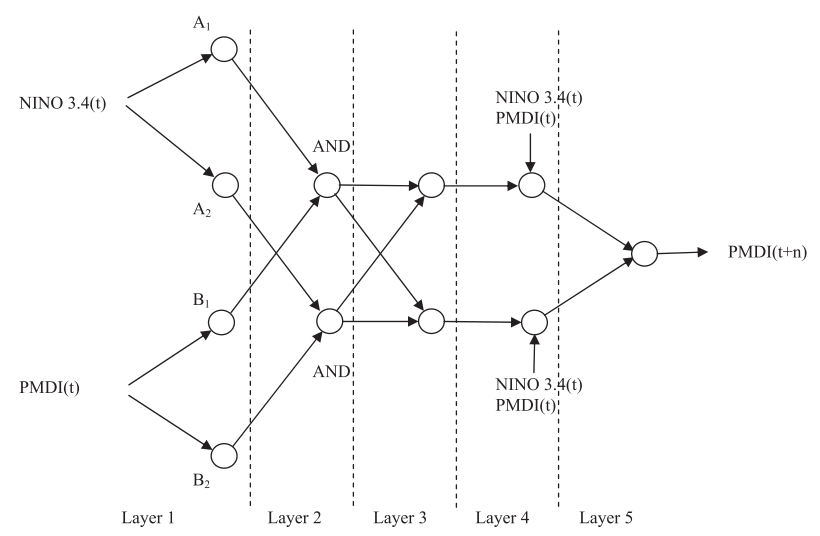

FIG. 3. Structure of ANFIS network.

An FL model consists of fuzzy rules and fuzzy sets that produce weightings for rules. Fuzzy rules appear in the form of IF-THEN statements, where the parts before and after THEN are called antecedent and consequent, respectively. In this study the antecedent part consists of ENSO indicators (e.g., Niño 3.4 or SOI) and previous PMDI values and the future PMDI values are used in the consequent part. For example, a simple fuzzy rule can be shown as "IF Niño3.4(t) is high and $\operatorname{PMDI}(t)$ is high THEN PMDI $(t+n)$ is high." Here, $n$ denotes the lead time in the resolution of months. There are mainly two approaches in the implementation of FL-namely, Mamdani and Takagi-Sugeno (TS) inference systems.

TABLE 1. Skill scores of scenarios employed for FL and ANN models; CC = correlation coefficient.

\begin{tabular}{|c|c|c|c|c|c|c|c|c|c|}
\hline \multirow[b]{3}{*}{ Model No. } & \multirow[b]{2}{*}{ Scenarios } & \multicolumn{4}{|c|}{ FL } & \multicolumn{4}{|c|}{ ANN } \\
\hline & & \multicolumn{2}{|c|}{ Train } & \multicolumn{2}{|c|}{ Test } & \multicolumn{2}{|c|}{ Train } & \multicolumn{2}{|c|}{ Test } \\
\hline & 3-month lead time & NSSS & $\mathrm{CC}$ & NSSS & $\mathrm{CC}$ & NSSS & $\mathrm{CC}$ & NSSS & $\mathrm{CC}$ \\
\hline 1 & Niño3.4 $(t), \operatorname{PMDI}(t)$ & 0.768 & 0.817 & 0.638 & 0.698 & 0.766 & 0.810 & 0.657 & 0.703 \\
\hline 2 & $\operatorname{Niño3.4}(t), \operatorname{PMDI}(t), \operatorname{PMDI}(t-1)$ & 0.666 & 0.815 & 0.501 & 0.720 & 0.673 & 0.820 & 0.474 & 0.698 \\
\hline 3 & Niño3.4(t), PMDI $(t), \operatorname{PMDI}(t-1), \operatorname{PMDI}(t-2)$ & 0.679 & 0.823 & 0.460 & 0.687 & 0.667 & 0.816 & 0.494 & 0.712 \\
\hline 4 & $\operatorname{PMDI}(t), \operatorname{PMDI}(t-1), \operatorname{PMDI}(t-2)$ & 0.667 & 0.816 & 0.491 & 0.705 & 0.673 & 0.820 & 0.411 & 0.662 \\
\hline 5 & $\begin{array}{l}\text { Niño3.4 }(t), \operatorname{PMDI}(t), \operatorname{PMDI}(t-1), \operatorname{PMDI}(t-2) \\
\quad \operatorname{PMDI}(t-3)\end{array}$ & 0.705 & 0.839 & 0.481 & 0.713 & 0.683 & 0.826 & 0.481 & 0.707 \\
\hline \multicolumn{10}{|c|}{ 6-month lead time } \\
\hline 6 & $\operatorname{Niño3.4}(t), \operatorname{PMDI}(t)$ & 0.497 & 0.662 & 0.213 & 0.437 & 0.476 & 0.647 & 0.213 & 0.416 \\
\hline 7 & Niño3.4(t), PMDI $(t), \operatorname{PMDI}(t-1)$ & 0.505 & 0.710 & 0.030 & 0.404 & 0.436 & 0.660 & 0.051 & 0.401 \\
\hline 8 & $\operatorname{Niño3.4}(t), \operatorname{PMDI}(t), \operatorname{PMDI}(t-1), \operatorname{PMDI}(t-2)$ & 0.434 & 0.658 & 0.106 & 0.422 & 0.476 & 0.689 & 0.097 & 0.422 \\
\hline 9 & $\operatorname{PMDI}(t), \operatorname{PMDI}(t-1), \operatorname{PMDI}(t-2)$ & 0.482 & 0.694 & 0.040 & 0.334 & 0.419 & 0.647 & -0.042 & 0.258 \\
\hline 10 & $\begin{array}{l}\text { Niño3.4(t), PMDI }(t), \operatorname{PMDI}(t-1), \operatorname{PMDI}(t-2) \\
\quad \operatorname{PMDI}(t-1)\end{array}$ & 0.502 & 0.708 & -0.031 & 0.407 & 0.414 & 0.642 & 0.133 & 0.421 \\
\hline \multicolumn{10}{|c|}{ 12-month lead time } \\
\hline 11 & $\operatorname{Niño3.4}(t), \operatorname{PMDI}(t)$ & 0.294 & 0.541 & -0.187 & 0.010 & 0.261 & 0.509 & -0.173 & -0.113 \\
\hline 12 & $\operatorname{Niño3.4(t),~PMDI~}(t), \operatorname{PMDI}(t-1)$ & 0.126 & 0.352 & -0.157 & -0.092 & 0.201 & 0.446 & -0.265 & -0.182 \\
\hline 13 & $\operatorname{Niño3.4(t),~PMDI~}(t), \operatorname{PMDI}(t-1), \operatorname{PMDI}(t-2)$ & 0.370 & 0.607 & -0.209 & -0.054 & 0.183 & 0.425 & -0.104 & -0.097 \\
\hline 14 & $\operatorname{PMDI}(t), \operatorname{PMDI}(t-1), \operatorname{PMDI}(t-2)$ & 0.198 & 0.443 & -0.189 & -0.087 & 0.272 & 0.520 & -0.286 & -0.050 \\
\hline 15 & $\begin{array}{l}\text { Niño3.4 }(t), \operatorname{PMDI}(t), \operatorname{PMDI}(t-1), \operatorname{PMDI}(t-2) \\
\quad \operatorname{PMDI}(t-3)\end{array}$ & 0.348 & 0.589 & -0.194 & 0.063 & 0.189 & 0.433 & -0.118 & -0.109 \\
\hline
\end{tabular}


TABLE 2. Skill scores for the prediction of full PMDI by WFL and WANN models; CC $=$ correlation coefficient.

\begin{tabular}{|c|c|c|c|c|c|c|c|c|c|}
\hline \multirow[b]{3}{*}{ Model No. } & \multirow{3}{*}{$\frac{\text { Scenarios }}{\text { 3-month lead time }}$} & \multicolumn{4}{|c|}{ WFL } & \multicolumn{4}{|c|}{ WANN } \\
\hline & & \multicolumn{2}{|c|}{ Train } & \multicolumn{2}{|c|}{ Test } & \multicolumn{2}{|c|}{ Train } & \multicolumn{2}{|c|}{ Test } \\
\hline & & NSSS & $\mathrm{CC}$ & NSSS & $\mathrm{CC}$ & NSSS & $\mathrm{CC}$ & NSSS & $\mathrm{CC}$ \\
\hline 1 & Niño3.4 $(t), \operatorname{PMDI}(t)$ & 0.613 & 0.794 & 0.555 & 0.761 & 0.764 & 0.874 & 0.555 & 0.758 \\
\hline 2 & $\begin{array}{l}\text { Niño3.4 }(t), \operatorname{PMDI}(t) \\
\quad \operatorname{PMDI}(t-1)\end{array}$ & 0.919 & 0.959 & 0.911 & 0.955 & 0.921 & 0.960 & 0.867 & 0.934 \\
\hline 3 & $\begin{array}{l}\text { Niño3.4(t), PMDI }(t) \\
\quad \operatorname{PMDI}(t-1), \operatorname{PMDI}(t-2)\end{array}$ & 0.920 & 0.959 & 0.906 & 0.952 & 0.920 & 0.961 & 0.818 & 0.908 \\
\hline 4 & $\begin{array}{l}\operatorname{PMDI}(t), \operatorname{PMDI}(t-1) \\
\quad \operatorname{PMDI}(t-2)\end{array}$ & 0.919 & 0.959 & 0.906 & 0.952 & 0.920 & 0.961 & 0.885 & 0.942 \\
\hline 5 & $\begin{array}{l}\text { Niño3.4(t), PMDI }(t) \\
\quad \operatorname{PMDI}(t-1), \operatorname{PMDI}(t-2) \\
\quad \operatorname{PMDI}(t-3)\end{array}$ & 0.845 & 0.921 & 0.814 & 0.905 & 0.840 & 0.919 & 0.785 & 0.888 \\
\hline & 6-month lead time & & & & & & & & \\
\hline 6 & Niño3.4(t), PMDI $(t)$ & 0.609 & 0.773 & 0.426 & 0.613 & 0.683 & 0.814 & 0.445 & 0.614 \\
\hline 7 & $\begin{array}{l}\text { Niño3.4 }(t), \operatorname{PMDI}(t) \\
\operatorname{PMDI}(t-1)\end{array}$ & 0.910 & 0.954 & 0.873 & 0.936 & 0.908 & 0.953 & 0.786 & 0.888 \\
\hline 8 & 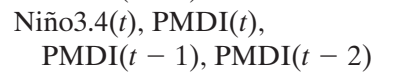 & 0.929 & 0.964 & 0.896 & 0.947 & 0.928 & 0.964 & 0.871 & 0.933 \\
\hline 9 & $\begin{array}{l}\operatorname{PMDI}(t), \operatorname{PMDI}(t-1) \\
\quad \operatorname{PMDI}(t-2)\end{array}$ & 0.928 & 0.963 & 0.903 & 0.951 & 0.936 & 0.968 & 0.773 & 0.883 \\
\hline 10 & $\begin{array}{l}\text { Niño3.4 }(t), \operatorname{PMDI}(t) \\
\quad \operatorname{PMDI}(t-1), \operatorname{PMDI}(t-2) \\
\quad \operatorname{PMDI}(t-1)\end{array}$ & 0.851 & 0.924 & 0.793 & 0.893 & 0.852 & 0.924 & 0.757 & 0.874 \\
\hline & 12-month lead time & & & & & & & & \\
\hline 11 & Niño3.4(t), PMDI $(t)$ & 0.610 & 0.783 & 0.399 & 0.649 & 0.487 & 0.697 & 0.364 & 0.603 \\
\hline 12 & $\begin{array}{l}\text { Niño3.4(t), PMDI }(t) \\
\operatorname{PMDI}(t-1)\end{array}$ & 0.843 & 0.920 & 0.778 & 0.884 & 0.858 & 0.927 & 0.695 & 0.862 \\
\hline 13 & $\begin{array}{l}\text { Niño3.4 }(t), \operatorname{PMDI}(t) \\
\quad \operatorname{PMDI}(t-1), \operatorname{PMDI}(t-2)\end{array}$ & 0.854 & 0.924 & 0.727 & 0.852 & 0.865 & 0.931 & 0.727 & 0.852 \\
\hline 14 & $\begin{array}{l}\operatorname{PMDI}(t), \operatorname{PMDI}(t-1) \\
\quad \operatorname{PMDI}(t-2)\end{array}$ & 0.844 & 0.919 & 0.756 & 0.870 & 0.853 & 0.923 & 0.700 & 0.851 \\
\hline 15 & $\begin{array}{l}\operatorname{Niño3.4}(t), \operatorname{PMDI}(t) \\
\quad \operatorname{PMDI}(t-1), \operatorname{PMDI}(t-2) \\
\quad \operatorname{PMDI}(t-3)\end{array}$ & 0.856 & 0.925 & 0.734 & 0.862 & 0.855 & 0.924 & 0.764 & 0.876 \\
\hline
\end{tabular}

While the Mamdani approach relies on expert knowledge, numerical data is important for the TS approach. Since data with long periods are available, here the TS system was used for forecasting. The significant spectral bands of ENSO indicators and previous drought index were used as input variables and output was taken as future values of the drought index, which is considered for forecasting. A schematic of the forecasting method is shown in Fig. 3.

For application of the TS FL model, one can refer to Takagi and Sugeno (1985) and Jang (1993). Assume that two inputs, Niño3.4(t) and $\operatorname{PMDI}(t)$, and one output, $\operatorname{PMDI}(t+n)$, form the following two rules for a first order TS type:

1) IF Niño3.4(t) is $\mathrm{A} 1$ and $\operatorname{PMDI}(t)$ is $\mathrm{B} 1 \mathrm{THEN}$

$$
\begin{aligned}
\operatorname{PMDI}(t+n)= & p_{11} \mathrm{Niño} 3.4(t)+p_{12} \operatorname{PMDI}(t) \\
& +p_{10}, \text { and }
\end{aligned}
$$

2) IF Niño3.4(t) is $\mathrm{A} 2$ and $\operatorname{PMDI}(t)$ is $\mathrm{B} 2$ THEN

$$
\operatorname{PMDI}(t+n)=p_{21} \operatorname{Niño3.4}(t)+p_{22} \operatorname{PMDI}(t)+p_{20}
$$

where A and B form linguistic labels, such as "low" or "high," and $p_{i j}$ variables are parameters. These fuzzy rules can express the relationship between input and output variables. The corresponding neuro-fuzzy network is shown in Fig. 3. A description of the layers in the network is as follows:

1) Each neuron in layer 1 is adaptive with a parametric activation function. Its output is the membership degree to which the given input satisfies the membership function-that is, $\mu_{A_{1}}[\mathrm{Niño3.4}(t)], \mu_{B_{1}}[\operatorname{PMDI}(t)], \mu_{A_{2}}$ (Niño3.4), $\mu_{B_{2}}$ [PMDI $\left.(t)\right]$. An example of a membership function is the generalized bell function: 



FIG. 4. Membership functions of Niño3.4(t) and PMDI $(t)$ 57-93-month spectral bands.

$$
\mu(x)=\frac{1}{1+\left|\frac{x-c}{a}\right|^{2 b}}
$$

where $a, b$, and $c$ are parameters. The shape of the bell function changes with parameters, which are called premise part parameters.

2) Layer 2 consists of fixed nodes. It produces outputs by multiplying all incoming signals. Firing strength $\alpha_{i}$ of the $i$ th rule is held in each node.

$3)$ Every node in layer 3 is fixed and calculates the ratio of the $i$ th rule's firing strength relative to the sum of all rules' firing strengths:

$$
\overline{a_{i}}=\frac{\alpha_{i}}{\alpha_{1}+\alpha_{2}} \quad i=1,2
$$

4) Layer 4 consists of adaptive nodes. The node output for this layer can be calculated as

$$
\begin{aligned}
& \overline{\alpha_{i}} \operatorname{PMDI}(t+n)_{i} \\
& =\overline{\alpha_{i}}\left[p_{i 1} \operatorname{Niño3.4}(t)+p_{i 2} \operatorname{PMDI}(t)+p_{i 0}\right] \quad i=1,2
\end{aligned}
$$

where $\overline{\alpha_{i}}$ is the normalized firing strength from layer 3 and $p_{i 1}, p_{i 2}$, and $p_{i 0}$ are the parameter sets of this node, which are also called consequent part parameters.

5) The resultant single node in layer 5 is a fixed node that calculates the weighted average of all incoming signals as

$$
\operatorname{PMDI}(t+n)=\frac{\sum_{i=n}^{n} \alpha_{i} \operatorname{PMDI}(t+n)_{i} \alpha_{i}}{\sum_{i=n}^{n} \alpha_{i}}
$$

A hybrid algorithm, called the adaptive neural fuzzy inference system (ANFIS), tunes the consequent parameters $\left(p_{i j}\right)$ in a forward propagation mode and premise parameters in a backward propagation mode (Jang 1993). In the forward propagation the network inputs are transmitted until layer 4 . The consequent parameters are determined by the least squares method. In the backward propagation, the error signals spread backward and a gradient descent method is employed to renew the premise parameters. Once the premise parameters are fixed, the overall output is a linear combination of the consequent parameters and input variables. The Matlab fuzzy logic toolbox is used for the fuzzy logic implementation.

\section{d. Wavelet and fuzzy logic combination}

The aim of the WFL combination model is to forecast $t$ months ahead PMDI from the Niño-3.4 index and persistence in PMDI. The continuous wavelet transform (CWT) is used to decompose the original series into their characteristic bands. The separation into significant spectral bands is conducted by considering the average wavelet spectra as mentioned above.

After decomposing the time series into several bands, each band of predictand is estimated from its corresponding predictor bands (Fig. 2). We employed the

\begin{tabular}{|c|c|c|c|}
\hline \multirow{2}{*}{$\begin{array}{l}\text { Niño3.4(t) (values of } \\
\text { 29-31-month spectral band) }\end{array}$} & \multicolumn{3}{|c|}{$\operatorname{PMDI}(\mathrm{t})$ (values of 29-31-month spectral band) } \\
\hline & Low & Medium & High \\
\hline Low & $\begin{aligned} y_{1}= & 1.368 \times \mathrm{Niño} 3.4(t)+0.509 \\
& \times \operatorname{PMDI}(t)+-0.881\end{aligned}$ & $\begin{aligned} y_{2}= & 0.298 \times \mathrm{Niño} 3.4(t)+0.657 \\
& \times \operatorname{PMDI}(t)+-0.149\end{aligned}$ & $\begin{aligned} y_{3}= & 0.356 \times \mathrm{Niño} 3.4(t)+0.73 \\
& \times \operatorname{PMDI}(t)+0.210\end{aligned}$ \\
\hline Medium & $\begin{aligned} y_{4}= & 2.196 \times \mathrm{Niño3.4}(t)+0.481 \\
& \times \operatorname{PMDI}(t)+-0.918\end{aligned}$ & $\begin{aligned} y_{5}= & 0.429 \times \mathrm{Niño} 3.4(t)+0.630 \\
& \times \operatorname{PMDI}(t)+-0.158\end{aligned}$ & $\begin{aligned} y_{6}= & 0.510 \times \mathrm{Niño} 3.4(t)+0.727 \\
& \times \operatorname{PMDI}(t)+0.205\end{aligned}$ \\
\hline High & $\begin{aligned} y_{7}= & 0.225 \times \mathrm{Niño3} .4(t)+0.513 \\
& \times \operatorname{PMDI}(t)+-0.855\end{aligned}$ & $\begin{aligned} y_{8}= & 1.339 \times \mathrm{Niño} 3.4(t)+0.485 \\
& \times \operatorname{PMDI}(t)+-0.336\end{aligned}$ & $\begin{aligned} y_{9}= & 0.111 \times \mathrm{Niño} 3.4(t)+0.499 \\
& \times \operatorname{PMDI}(t)+0.390\end{aligned}$ \\
\hline
\end{tabular}
fuzzy logic model to relate the predictand and the predictors. Since the aim of this study is to make predictions

TABLE 3. Fuzzy rule base for the 29-31-month spectral band of model 1. The predictors are the 29-31-month spectral band of Niño3.4( $t)$ and $\operatorname{PMDI}(t)$ and the predictand is the 29-31-month spectral band of $\operatorname{PMDI}(t+3)$. 


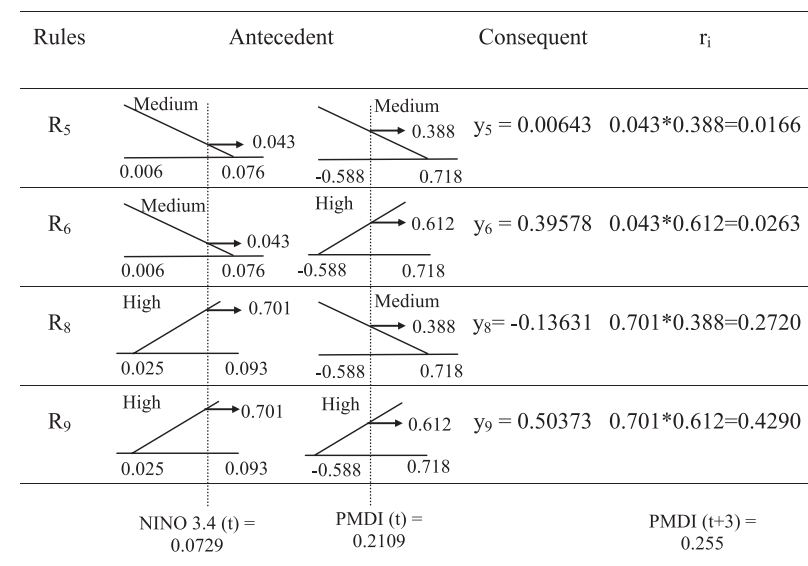

FIG. 5. A sample TS fuzzy inference system for the 57-93-month spectral band of the model 1.

for future time, past data are used in the forecasts. As a final step, spectral bands of predictand are reconstructed to produce the single time series of PMDI.

If one desires to make a forecast starting at $t=t_{1}$ for a future time $t=t_{2}$, only data measured prior to $t=t_{1}$ should be used. Therefore, each future value can be forecasted by the fuzzy logic model independently. For instance, PMDI data are available from 1951 to current date on a monthly basis. A 3-month-ahead forecast of PMDI from October 2009 should use data from January 1951 until October 2009.

Application of the WFL model consists of three steps: 1) decomposition of ENSO indicators and PMDI into their spectral bands by using average wavelet spectra, 2) using the fuzzy logic approach to achieve the forecasting of PMDI spectral bands from the spectral bands of ENSO indicators and previous PMDI, and 3) reconstructing the predicted spectral bands of predictand to obtain forecasts.

\section{Results and discussion}

\section{a. FL model}

In this study, 3-, 6-, and 12-month lead times were considered for drought forecasting. For each of the three lead times, the TS FL model was used with and without considering wavelet spectral bands. First, the original time series was used for forecasting. For this purpose, data (1951-2006) were split into two parts-namely, training (calibration) and testing. The last $20 \mathrm{yr}$ of the entire dataset (56 yr, 672 months) was employed for testing and the remaining part was used for training. Trial and error was used to select the predictors used in each model. Since it is known from the literature that persistence plays an important role in forecasting droughts, the previous drought measurements were used as predictand. The effect of ENSO indices on the forecasting performance was also explored. Using ENSO indices alone without considering persistence produced poor results. Different scenarios were tried, as shown in Tables 1 and 2.

The number of current and previous input variables that corresponded to the number of lagged observations of Niño-3.4 and PMDI were used to determine the underlying pattern in a time series and forecast future values. Using input information, the TS FL model had an ability to detect the feature, capture the pattern in the data, and perform nonlinear mapping between input and output variables. For 3-month-ahead forecasting, the model with input variables Niño3.4(t) and $\operatorname{PMDI}(t)$ yielded the best training and testing results (Table 1 ). Increasing the number of lags did not improve the model performance any more.

\section{b. WFL model}

Prior to discussing the results, a sample explanation of the TS fuzzy inference system along with a numerical application is given in what follows. Each of the predictor and predictand time series was decomposed into six significant spectral bands as described in section $3 \mathrm{~b}$. For prediction, it was required to establish six fuzzy models and reconstruct the final prediction by using each predicted spectral band. Here, the sample fuzzy inference was given only for one specific spectral band (57-93 months) of the model 1. In this model, Niño3.4(t) and $\operatorname{PMDI}(t)$ were the predictors and $\operatorname{PMDI}(t+3)$ was the predictand. The ANFIS training algorithm was employed to refine the parameters of input membership functions and linear functions in the consequent part of the fuzzy rule. Membership functions obtained after running the ANFIS algorithm are shown in Fig. 4. Since both predictors had three membership functions, there were $3 \times 3=9$ rules in the fuzzy rule base. The consequent part parameters of these rules were determined by ANFIS. Table 3 includes a description of the fuzzy rule base for the model under consideration.

A sample inference procedure is given in Fig. 5. The given Niño3.4 0.0729 is a value in the 29-31-month band of Niño3.4, and $\operatorname{PMDI}(t)=0.2109$ is a value in the 29-31-month band of PMDI; fuzzy subsets medium and high for Niño3.4(t) and medium and high for $\operatorname{PMDI}(t)$ were triggered. The membership degrees yielded by inputs can be seen in the antecedent part of Fig. 5. The consequent value $\left(y_{i}\right)$ for each rule that was a linear combination of inputs was calculated using functions given in Table 3. Weights $\left(r_{i}\right)$ for each rule were determined using fuzzy prod operator because the antecedent part consisted of more than one input. Results of the prod operator are shown in the last column of Fig. 5. In the last step, the weighted average of each rule was computed as 
(a) 3-month lead time, Model-2

$\circ$ Observed

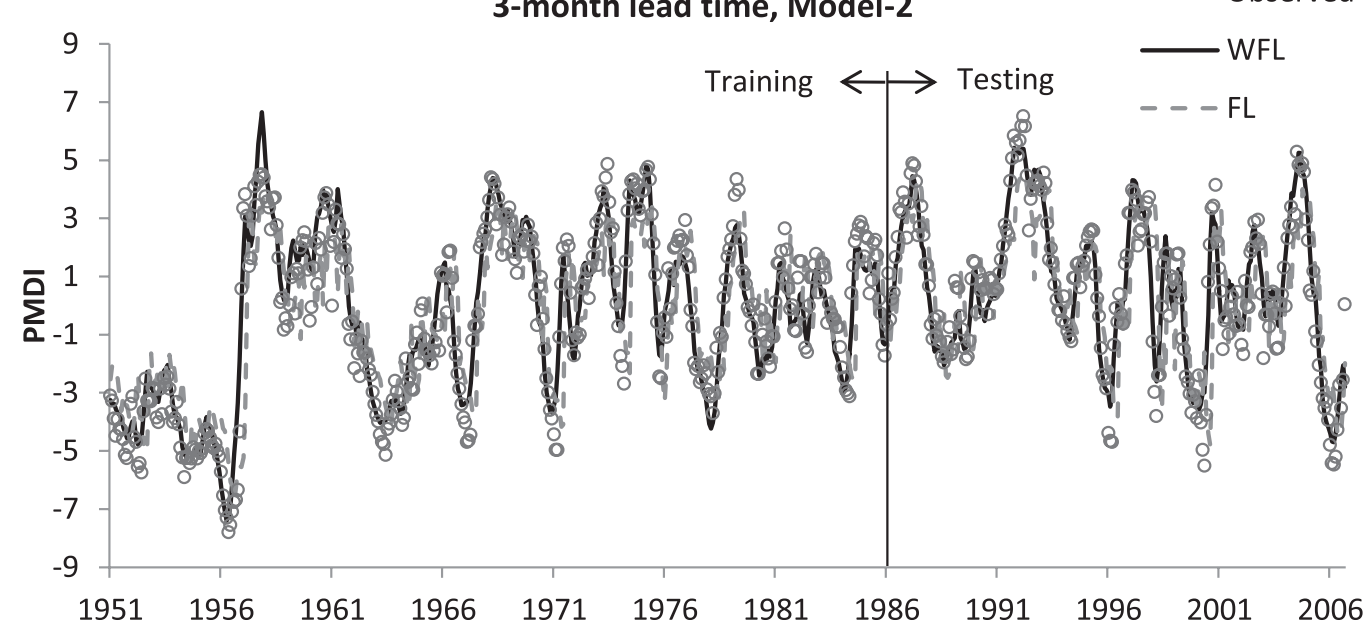

(b)

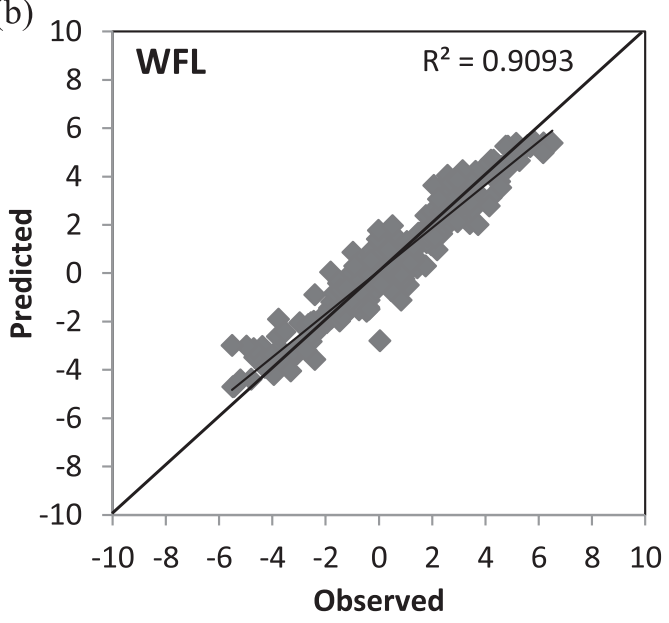

(c)

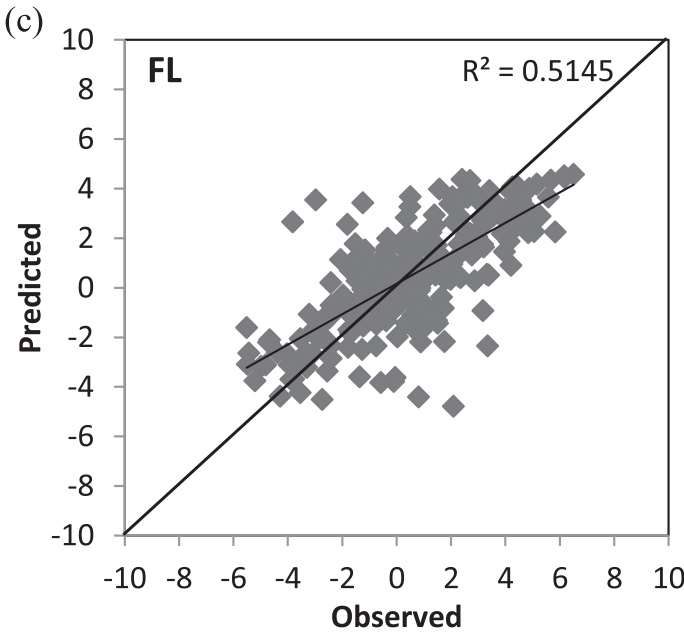

FIG. 6. For 3-month lead time forecasting, model 2 is selected for comparison. (a) Time series comparison of observed series with FL and WFL; scatter of observed and predicted points for testing period around perfect model line for (b) WFL and (c) FL models.

$$
\operatorname{PMDI}(t+3)=\frac{(0.017 \times 0.006)+(0.026 \times 0.396)+(0.272 \times-0.136)+(0.429 \times 0.504)}{0.017+0.026+0.272+0.429}=0.255
$$

To evaluate the model accuracy, the Nash-Sutcliffe sufficiency score (NSSS) and correlation coefficient were used. NSSS is defined as one minus the ratio of mean-square error and observation variance, and takes on values between $-\infty$ and 1 , where 1 shows the perfect model. In the present study, input variables for the FL model corresponded to the subseries of Niño3.4 and the previous observations of PMDI. Up to four previous values that were tested for all PMDI series lay within this range. It was seen that the forecast accuracy decreased beyond the three previous values. To improve model results, the wavelet bands of input and output variables were taken into account. The improvement was clearly seen when results were compared with the case where wavelet bands were not used (Tables 1 and 2).

The forecast performance of the WFL model for each scenario is presented in Table 2. The forecast validation was done on raw (unfiltered) data. From the results it was observed that the WFL model provided an improvement for long lead drought forecasting over the FL model. As seen from the table, model 2 had the highest NSSS value among the WFL models for 3-month lead time when the testing period was considered. The NSSS 
(a)



(b)

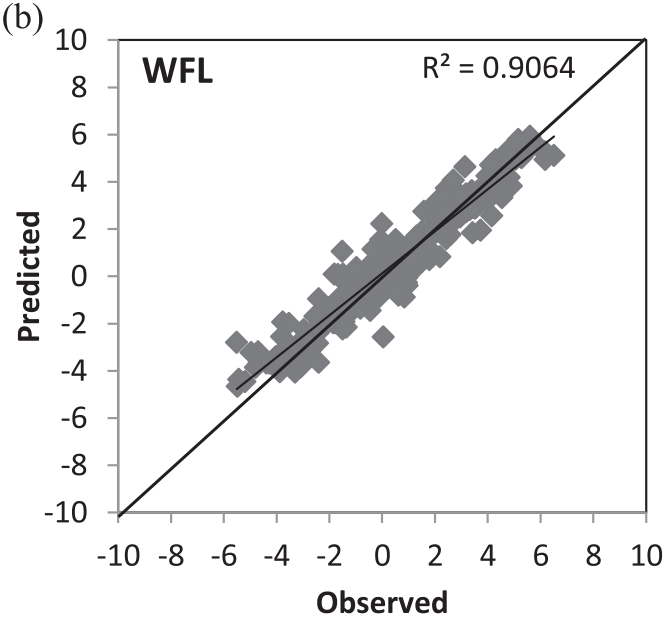

(c)

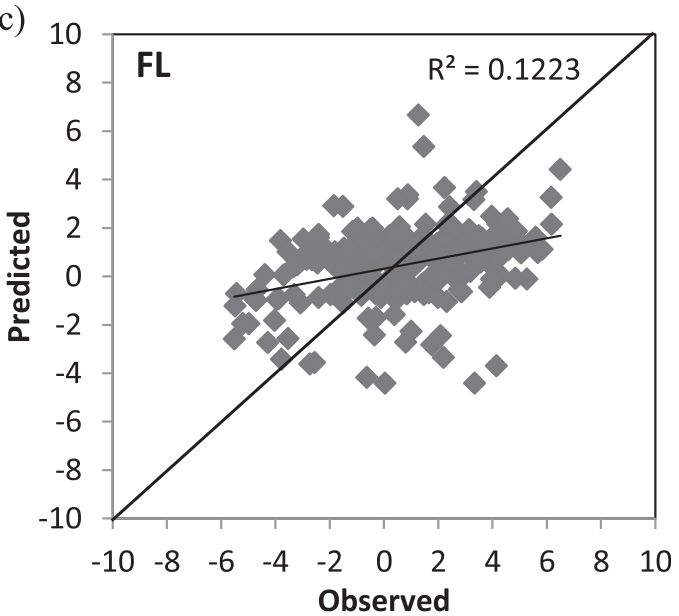

FIG. 7. Same as Fig. 6 but for 6-month lead time forecasting, with model 9 selected for comparison.

value of 0.501 obtained by the FL model was increased to 0.911 with the aid of the wavelet transform. The increment of the model results can be explained with the elimination of some noisy data. Since the ENSOrelated drought occurrences developed in low frequencies, the removal of noisy and high-frequency data captured the characteristics of PMDI variable more consistently.

Among several scenarios, it is also worth noting that persistence provided a valuable tool for PMDI forecasting. For 3-month lead time forecasting, observed and forecasted time series of PMDI are shown in Fig. 6a. Forecasted values with the FL model exhibited more scatter around the exact model line as compared to the WFL model (Figs. 6b and 6c). For a longer lead time, deterioration in the model performance is expected.

For 6-month lead time forecasting, models 8 and 9 gave better results than others for the testing period.
Compared to the FL model, which yielded 0.106 and 0.040 as NSSS scores for models 8 and 9, respectively, WFL models increased the accuracy to around 0.90 . This is also evident from Fig. 7.

Most of the time, various models for 12-month lead time forecasting have difficulties reaching the desired accuracy. However, this problem was addressed in this study by employing the WFL model. The NSSS values with negative numbers produced by FL were improved up to 0.78 by WFL for test results. This remarkable improvement can have a significant impact on long-range forecasting. Model 12 gave higher NSSS values for testing result. Niño 3.4 along with the two past values of PMDI yielded better results compared to others. Related results can be seen from Fig. 8 . It is also worth mentioning that lagged values of PMDI along with Niño 3.4 contributed to most of the model capability. 
(a) 12-month lead time, Model-12

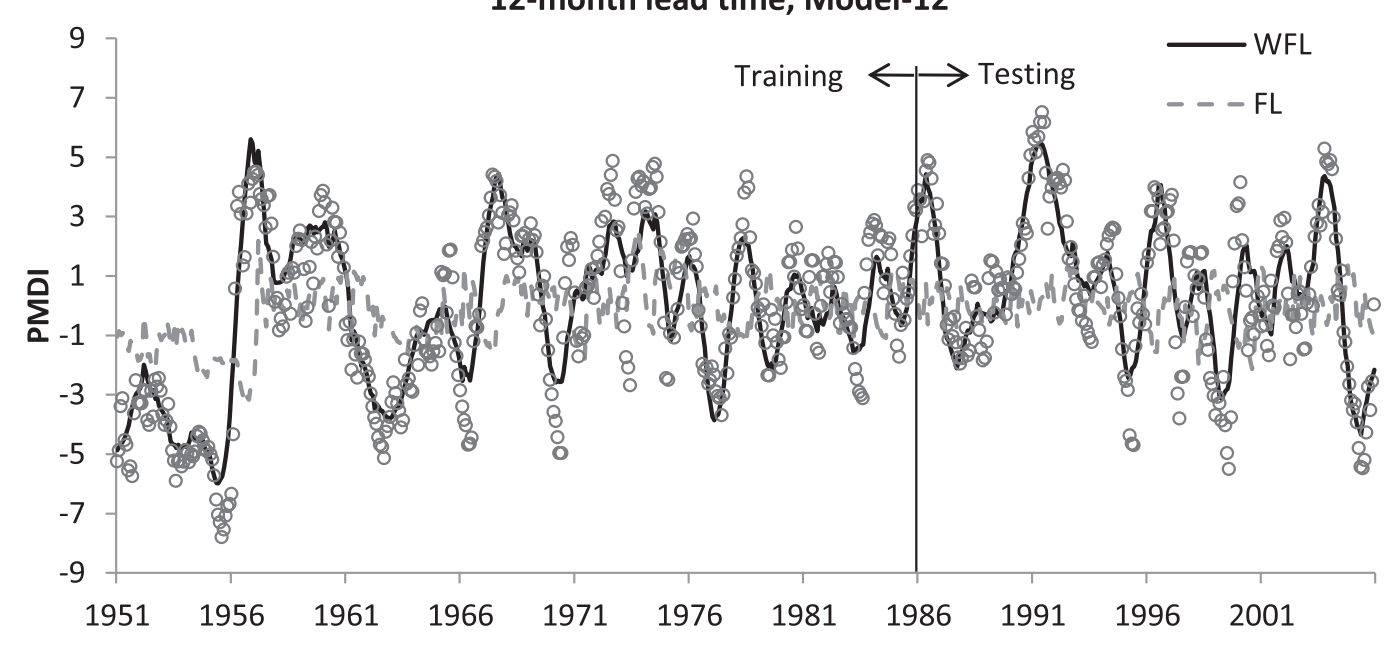

(b)

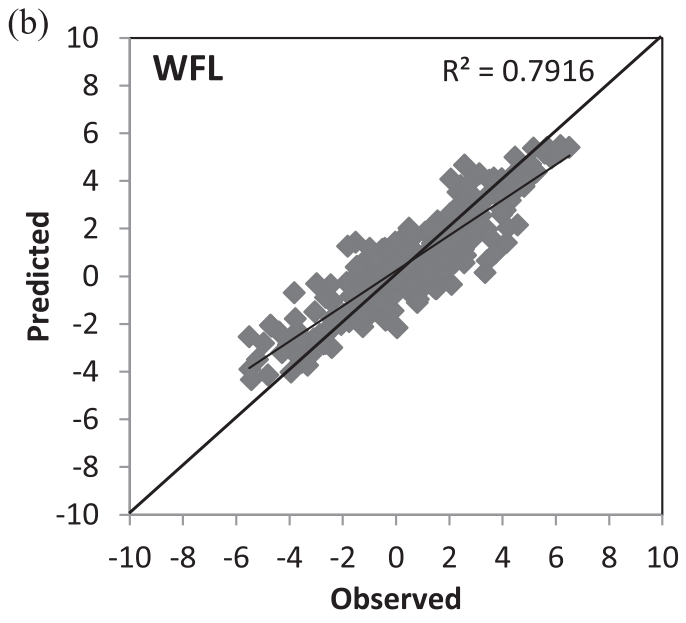

(c)

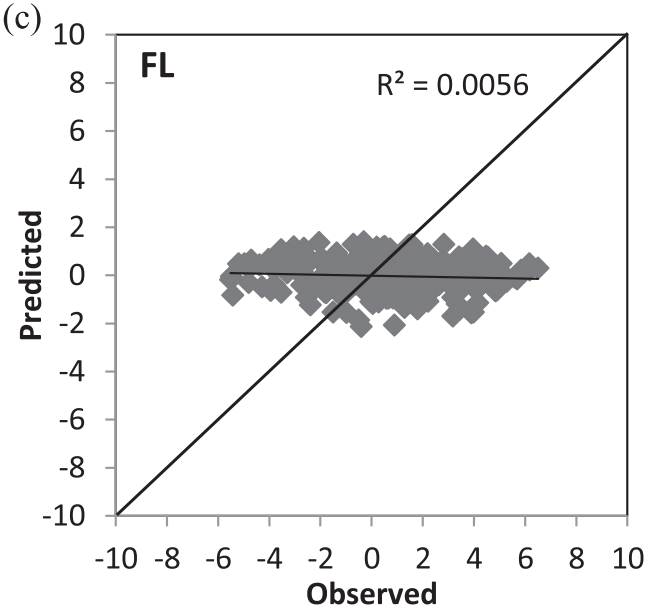

FIG. 8. Same as Fig. 6 but for 12-month lead time forecasting, with model 12 selected for comparison.

\section{c. Comparison with ANN and wavelet ANN models}

The proposed combination model was compared with the results obtained from ANN and wavelet ANN (WANN) models. The same input configurations were used for comparison. The best ANN models, for all configurations, have a relatively simple architecture. Three layer networks and a maximum of five neurons for a hidden layer are sufficient to produce results for all lead times. It is particularly important to ensure that accurate long-term forecasts with lead times of 3-12 months are obtained for drought preparedness. The ANN models developed in this paper resulted in the NSSS values for 6-month lead time ranging from 0.414 to 0.478 for training data and -0.042 to 0.213 for testing data, indicating poor forecasting accuracy.
The coupled ANN and wavelet model was used to forecast PMDI values. An experimental selection of the neural network architecture was based on the error score. Nearly the same simple architectures were obtained with ANN. The use of WANN allowed for generating forecasts of PMDI. For a 6-month lead time, the WANN model NSSS scores ranged from 0.682 to 0.936 for training data and 0.445 to 0.870 for testing data, which indicates a reasonable improvement over the ANN results.

The overall results for all approaches used in this study are presented in Tables 1 and 2. The ANN model results are close to the FL model. The FL model slightly outperformed ANN in most of the cases. Also, the advantage of wavelet decomposition is seen even when the ANN and WANN results are compared with each other. For instance, for a 6-month lead time forecast by model 8 , ANN and WANN yielded the 
NSSS values of 0.097 and 0.871 for testing data, respectively.

Although the WANN produces results that are close to the WFL model, there is a remarkable difference that can be seen when testing data scores are considered. The difference between them is apparent when more lead time was taken into account.

There are often high nonlinear interacting mechanisms in the climate system that need to be taken into consideration. Since the ENSO variability is not a global precursor of drought, it is highly unlikely that a datadriven model as proposed here will be directly applicable elsewhere without significant work to identify appropriate independent predictors.

\section{Conclusions}

The wavelet fuzzy logic model was developed and applied for long lead time drought forecasting. While PMDI was chosen as a predictand, the ENSO indicator, Niño3.4, and previous PMDI values were used as predictors. The wavelet transform was used to analyze the variation of spectral power. Here the continuous wavelet transform was employed to obtain the average wavelet spectra. The significant spectral bands were detected from the average wavelet spectra for predictors and predictand. Six bands that contain significant power were determined. The Takagi-Sugeno fuzzy inference system was employed to relate predictor bands to predictand bands. Six different scenarios were taken into consideration. For each scenario a specific fuzzy model was constructed to obtain results.

WFL provided a remarkable improvement in the model accuracy over FL. Comparison between WFL and FL model results for three different lead times (3, 6, 12 months) showed the superiority of WFL. It is possible to make more accurate forecasts for a 12-month lead time in the level of NSSS $=0.778$ with WFL. Application of the wavelet fuzzy model showed that the lagged values of PMDI are important predictors for drought forecasting. The 12-month-ahead forecasting with acceptable accuracy can be used as a tool for drought management. It is clear that the WFL model is in good agreement with observed data. Also, the proposed model results were compared with ANN and WANN. It is seen that WFL forecasts are superior to the ones yielded by FL and ANN models.

Acknowledgments. The authors would like to sincerely thank the editor and two anonymous reviewers for their constructive comments. This work was financially supported in part by the U.S. Geological Survey (USGS, Project ID 2009TX334G) and TWRI through the project
Hydrological Drought Characterization for Texas under Climate Change, with Implications for Water Resources Planning and Management, and by the National Research Foundation Grant funded by the Korean Government (MEST) (NRF-2009-220-D00104).

\section{APPENDIX}

\section{Acronyms}

ANN Artificial neural network

ANFIS Adaptive neural fuzzy inference system

ARIMA Autoregressive integrated moving average

CP Circulation patterns

CWT Continuous wavelet transform

DMSNN Direct multistep neural network

EDI Effective drought index

ENSO El Niño-Southern Oscillation

FL Fuzzy logic

FT Fourier transform

NAO North Atlantic Oscillation

Niño 3.4 Mean sea surface temperature at $5^{\circ} \mathrm{N}-5^{\circ} \mathrm{S}$ and $170^{\circ}-120^{\circ} \mathrm{W}$

NOAA National Oceanic and Atmospheric Administration

PDI Palmer drought index

PDSI Palmer drought severity index

PMDI Modified PDSI

RMSNN Recursive multistep neural network

SOI Southern Oscillation index

SPI Standard precipitation index

SST Sea surface temperature

WFL Wavelet fuzzy logic

\section{REFERENCES}

Alfaro, E. J., A. Gershunov, and D. Cayan, 2006: Prediction of summer maximum and minimum temperature over the central and western United States: The roles of soil moisture and sea surface temperature. J. Climate, 19, 1407-1421.

Alley, W. M., 1984: The Palmer Drought Severity Index: Limitations and assumptions. J. Climate Appl. Meteor., 23, 1100-1109.

Aussem, A., and F. Murtagh, 1997: Combining neural network forecasts on wavelet-transformed time series. Connect. Sci., 9, 113-121.

Barlow, M., S. Nigam, and E. H. Berbery, 2001: ENSO, Pacific decadal variability, and U.S. summertime precipitation, drought, and streamflow. J. Climate, 14, 2105-2128.

Barros, A. P., and G. J. Bowden, 2008: Toward long-lead operational forecasts of drought: An experimental study in the Murray-Darling River Basin. J. Hydrol., 357 (3-4), 349-367.

Busby, S. J., K. R. Briffa, and T. J. Osborn, 2007: Simulation of ENSO forcings on U.S. drought by the HadCM3 coupled climate model. J. Geophys. Res., 112, D18112, doi:10.1029/2007JD008705. 
Cancelliere, A., G. Di Mauro, B. Bonaccorso, and G. Rossi, 2005: Stochastic forecasting of Standardized Precipitation Index. Proc. 31st IAHR Congress, Seoul, Korea, IAHR, 3252-3260.

Coelho, C. A. S., and L. Goddard, 2009: El Niño-induced tropical droughts in climate change projections. J. Climate, 22, 6456-6476.

Cole, J., J. T. Overpeck, and E. R. Cook, 2002: Multi-year La Niña events and persistent drought in the contiguous United States. Geophys. Res. Lett., 29, 1647, doi:10.1029/2001GL013561.

Feng, S., R. J. Oglesby, C. M. Rowe, D. B. Loope, and Q. Hu, 2008: Atlantic and Pacific SST influences on medieval drought in North America simulated by the Community Atmospheric Model. J. Geophys. Res., 113, D11101, doi:10.1029/2007JD009347.

Gabor, D., 1946: Theory of communication. J. Inst. Electr. Eng., 93, 429-457.

Gan, T. Y., A. K. Gobena, and Q. Wang, 2007: Precipitation of southwestern Canada: Wavelet, scaling, multifractal analysis, and teleconnection to climate anomalies. J. Geophys. Res., 112, D10110, doi:10.1029/2006JD007157.

Goddard, L., A. G. Barnston, and S. J. Mason, 2003: Evaluation of the IRI's "net assessment" seasonal climate forecasts: 19972001. Bull. Amer. Meteor. Soc., 84, 1761-1781.

Heddinghaus, T. R., and P. Sabol, 1991: A review of the Palmer Drought Severity Index and where do we go from here? Proc. Seventh Conf. on Applied Climatology, Salt Lake City, UT, Amer. Meteor. Soc., 242-246.

Heim, R. R., Jr., 2002: A review of twentieth-century drought indices used in the United States. Bull. Amer. Meteor. Soc., 83, $1149-1165$.

Hiller, T. L., and L. A. Powell, 2009: Long-term agricultural landuse trends in Nebraska, 1866-2007. Great Plains Res., 19, 225-237.

Jang, J.-S. R., 1993: ANFIS: Adaptive-network-based fuzzy inference system. IEEE Trans. Syst. Man Cybern., 23, 665-684.

Jevrejeva, S., J. C. Moore, and A. Grinsted, 2003: Influence of the Arctic Oscillation and El Niño-Southern oscillation (ENSO) on ice conditions in the Baltic Sea: The wavelet approach. J. Geophys. Res., 108, 4677, doi:10.1029/2003JD003417.

Kahya, E., and J. A. Dracup, 1993: U.S. streamflow patterns in relation to the El Niño/Southern Oscillation. Water Resour. Res., 29, 2491-2503.

— , and - 1994: The relationships between U.S. streamflow and La Niña events. Water Resour. Res., 30, 2133-2141.

Kim, T. W., and J. B. Valdes, 2003: Nonlinear model for drought forecasting based on a conjunction of wavelet transforms and neural networks. J. Hydrol. Eng., 8, 319-328.

Küçük, M., E. Kahya, T. M. Cengiz, and M. Karaca, 2009: North Atlantic Oscillation influences on Turkish lake levels. Hydrol. Processes, 23, 893-906.

Kumar, P., and E. Foufoula-Georgiou, 1997: Wavelet analysis for geophysical applications. Rev. Geophys., 35, 385-412.

Kwon, H.-H., U. Lall, and A. F. Khalil, 2007: Stochastic simulation model for nonstationary time series using an autoregressive wavelet decomposition: Applications to rainfall and temperature. Water Resour. Res., 43, W05407, doi:10.1029/ 2006WR005258.

Lohani, V. K., and G. V. Loganathan, 1997: An early warning system for drought management using the Palmer drought index. J. Amer. Water Resour. Assoc., 33, 1375-1386.

Mishra, A. K., and V. R. Desai, 2005: Drought forecasting using stochastic models. Stochastic Environ. Res. Risk Assess., 19, 326-339.

$\longrightarrow$, and - 2006: Drought forecasting using feed-forward recursive neural network. Ecol. Modell., 198, 127-138.
- , and V. P. Singh, 2010: A review of drought concepts. J. Hydrol., 391 (1-2), 202-216.

— , and — 2011: Drought modeling—A review. J. Hydrol., 403 (1-2), 157-175, doi:10.1016/j.jhydrol.2011.03.049.

—, V. R. Desai, and V. P. Singh, 2007: Drought forecasting using a hybrid stochastic and neural network model. J. Hydrol. Eng., 12, 626-638.

Misiti, M., Y. Misiti, G. Oppenheim, and J. Poggi, 2000: Wavelet Toolbox: For Use with MATLAB. MathWorks, 941 pp.

Mo, K. C., J. K. E. Schemm, and S. H. Yoo, 2009: Influence of ENSO and the Atlantic multidecadal oscillation on drought over the United States. J. Climate, 22, 5962-5982.

Morid, S., V. Smakhtin, and K. Bagherzadeh, 2007: Drought forecasting using artificial neural networks and time series of drought indices. Int. J. Climatol., 27, 2103-2111.

NOAA, cited 2008: Divisional data select. [Available online at http://www7.ncdc.noaa.gov/CDO/CDODivisionalSelect.jsp\#.]

Özger, M., A. K. Mishra, and V. P. Singh, 2009: Low frequency drought variability associated with climate indices. J. Hydrol., 364 (1-2), 152-162.

Palmer, W. C., 1965: Meteorological drought. U.S. Weather Bureau Tech. Paper 45, 58 pp. [Available from NOAA/National Weather Service, 1325 East West Highway, Silver Spring, MD 20910.]

Partal, T., and O. Kisi, 2007: Wavelet and neuro-fuzzy conjunction model for precipitation forecasting. J. Hydrol., 342 (1-2), 199-212.

— , and H. K. Cigizoglu, 2008: Estimation and forecasting of daily suspended sediment data using wavelet-neural networks. J. Hydrol., 358 (3-4), 317-331.

— , and — 2009: Prediction of daily precipitation using wavelet-neural networks. Hydrol. Sci. J., 54, 234-246.

Pesti, G., B. P. Shrestha, L. Duckstein, and I. Bogárdi, 1996: A fuzzy rule-based approach to drought assessment. Water Resour. Res., 32, 1741-1747.

Pongracz, R., B. Bogardi, and L. Duckstein, 1999: Application of fuzzy rule-based modeling technique to regional drought. J. Hydrol., 224, 100-114.

Rajagopalan, B., M. E. Mann, and U. Lall, 1998: A multivariate frequency-domain approach to long-lead climatic forecasting. Wea. Forecasting, 13, 58-74.

— E. Cook, U. Lall, and B. Ray, 2000: Spatiotemporal variability of ENSO and SST teleconnections to summer drought over the United States during the twentieth century. J. Climate, 13, 4244-4255.

Rao, A. R., and G. Padmanabhan, 1984: Analysis and modeling of Palmer's drought index series. J. Hydrol., 68, 211-229.

Rhee, J., and G. J. Carbone, 2007: A comparison of weekly monitoring methods of the Palmer Drought Index. J. Climate, 20, 6033-6044.

Saco, P., and P. Kumar, 2000: Coherent modes in multiscale variability of streamflow over the United States. Water Resour. Res., 36, 1049-1068.

Tadesse, T., D. A. Wilhite, M. J. Hayes, S. K. Harms, and S. Goddard, 2005: Discovering associations between climatic and oceanic parameters to monitor drought in Nebraska using data-mining techniques. J. Climate, 18, 1541-1550.

Takagi, T., and M. Sugeno, 1985: Fuzzy identification of systems and its application to modeling and control. IEEE Trans. Syst. Man Cybern., 15, 116-132.

Tootle, G. A., and T. C. Piechota, 2006: Relationships between Pacific and Atlantic ocean sea surface temperatures and U.S. streamflow variability. Water Resour. Res., 42, W07411, doi:10.1029/2005WR004184. 
- - , and A. Singh, 2005: Coupled oceanic-atmospheric variability and U.S. streamflow. Water Resour. Res., 41, W12408, doi:10.1029/2005WR004381.

Torrence, C., and G. P. Compo, 1998: A practical guide to wavelet analysis. Bull. Amer. Meteor. Soc., 79, 61-78.

Webster, P. J., and C. D. Hoyos, 2004: Prediction of monsoon rainfall and river discharge on 15-30-day time scales. Bull. Amer. Meteor. Soc., 85, 1745-1765.

Zadeh, L. A., 1965: Fuzzy sets. Inf. Control, 12, 94-102.
Zhang, B. L., and Z. Y. Dong, 2001: An adaptive neural-wavelet model for short term load forecasting. Electr. Power Syst. Res., 59, 121-129.

Zheng, T., A. A. Girgis, and E. B. Makram, 2000: A hybrid waveletKalman filter method for load forecasting. Electr. Power Syst. Res., 54, 11-17.

Zhou, H., Y. Peng, and G. Liang, 2008: The research of monthly discharge predictor-corrector model based on wavelet decomposition. Water Resour. Manage., 22, 217-227. 